\title{
Commissioning and First Results of the ITER-Relevant Negative Ion Beam Test Facility ELISE
}

\author{
P. Franzen, B. Heinemann, U. Fantz, D. Wünderlich, W. Kraus, M. Fröschle, C. Martens, \\ R. Riedl, R. Nocentini, A. Masiello*, B. Ruf, L. Schiesko, C. Wimmer and NNBI Team \\ Max-Planck-Institut für Plasmaphysik, EURATOM Association, Boltzmannstraße 2, \\ 85748 Garching, Germany \\ * Fusion for Energy, C/ Josep Pla 2, 08019 Barcelona, Spain
}

E-mail contact of main author: peter.franzen@ipp.mpg.de

\begin{abstract}
The test facility ELISE which was constructed in the last three years at the Max-Planck-Institut für Plasmaphysik (IPP), Garching, is an important intermediate step of the development of the neutral beam system for ITER. ELISE allows gaining an early experience of the performance and operation of large RF driven sources for negative hydrogen ions and will give an important input for the commissioning and the design of the SPIDER and MITICA test facilities at Padua and the ITER neutral beam system. ELISE has gone recently into operation with first plasma and beam pulses. The experiments aim at the demonstration of an ion beam at the required parameters within 2 years of operation until end of 2014, the end of the service contract with F4E for the establishment and exploitation of ELISE.
\end{abstract}

\section{Introduction}

For heating and current drive the ITER NBI system [1,2] requires a negative hydrogen ion

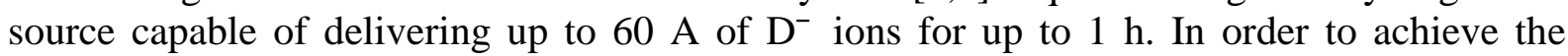
required $40 \mathrm{~A}$ of accelerated current at $1 \mathrm{MeV}$ - corresponding to an accelerated current density of $200 \mathrm{~A} / \mathrm{m}^{2}$ — and to limit the power loads in the extraction system, the ion losses in the accelerator must be minimized by operating the source at a pressure of $0.3 \mathrm{~Pa}$ and the amount of co-extracted electrons must not exceed the amount of extracted negative ions. As presently these parameters have not yet been achieved simultaneously, also due to a lack of adequate test facilities, the European ITER domestic agency F4E has defined an R\&D roadmap for the construction of the neutral beam heating systems [3,4]. An important step herein is the new test facility ELISE (Extraction from a Large Ion Source Experiment) for a large-scale extraction from a half-size ITER RF source which was constructed in the last years at Max-Planck-Institut für Plasmaphysik (IPP) and is now operational. The early experience of the operation of such a large RF driven source $(1 \mathrm{~m} \times 0.9 \mathrm{~m}$ with an extraction area of $0.1 \mathrm{~m}^{2}$ ) will give an important input for the design of the Neutral Beam Test Facility PRIMA in Padova [5] and the ITER NBI systems (heating beams and diagnostic beam [6,7], the latter being built by India) and for their commissioning and operating phases. PRIMA consists of the $1 \mathrm{MeV}$ full power test facility MITICA [8], operational in 2017, and the $100 \mathrm{kV}$ ion source test facility SPIDER [9], operational in 2015.

The aim of the design of the ELISE source and extraction system (see the parameters in table 1) was to be as close as possible to the ITER design [10,11]; it has however some modifications allowing a better diagnostic access as well as more flexibility for exploring open questions. The extraction system is designed for acceleration of negative hydrogen ions of up to $60 \mathrm{kV}$. Plasma operation of up to $1 \mathrm{~h}$ is foreseen; but due to the limits of the IPP HV system, pulsed extraction only is possible, i.e. beam pulses of $10 \mathrm{~s}$ maximum can be done every 150 - 180 s with the plasma continuously running. It had been demonstrated by the 
long pulse test facility MANITU at IPP, equipped with a small prototype source, that this kind of operation does not influence the source performance [12].

In order to obtain the large required negative hydrogen ion currents, the socalled surface generation process must be used: the negative ions are created by the conversion mainly of hydrogen atoms [13] at a surface with a sufficiently low work function. The latter is achieved by evaporation of cesium into the source. Due to the short survival length of the negative hydrogen ions (some cm's), only ions created at the first grid of the extraction system, the plasma grid (PG), have a non-negligible extraction probability [14].

FIG. 1 shows a cut through the ELISE source. The plasma is generated in four cylindrical drivers (instead of eight as for the ITER source) with a diameter of $300 \mathrm{~mm}$. The RF power is coupled inductively into the plasma via a six-turn copper coil wound around an $\mathrm{Al}_{2} \mathrm{O}_{3}$ insulator; the latter is protected from plasma sputtering by an actively cooled copper Faraday screen. As it is the case also for the ITER NBI sources, each RF generator - ELISE is equipped with two having a maximum power of $180 \mathrm{~kW}$ each - feeds a pair of two horizontal drivers in series. The ELISE extraction system is designed for acceleration of negative hydrogen ions of up to $60 \mathrm{kV}$. It consists of three grids: the plasma grid (PG) which separates the plasma from the beam region, the extraction grid (EG), where the co-extracted electrons are filtered out of the beam by the embedded magnets, and the grounded grid (GG). Each grid has 640 extraction apertures with a diameter of 14 $\mathrm{mm}$ (PG and GG) and $11 \mathrm{~mm}$ (EG), respectively, and consists of two individual segments in a vertical arrangement, i.e. a top and a bottom segment. The drivers are operated in vacuum; they are enclosed by the so-called dome with its vacuum being separated from the source vacuum.

The main issues that will be addressed by ELISE are (1) the influence of the new magnetic filter field (see below) on the extracted current densities of ions and electrons, (2) the homogeneity of the plasma and, most important, the beam, and (3) the dynamics of the Cs distribution in a large ion source. All issues are connected as the homogeneity of the plasma is influenced by
TABLE I: PARAMETERS OF THE ELISE TEST FACILITY

\begin{tabular}{|l|l|}
\hline Isotope & $\mathrm{H}, \mathrm{D}$ (limited beam time/year \\
\hline Extraction area & $1000 \mathrm{~cm}^{2}$ \\
\hline Apertures & $640, \varnothing 14 \mathrm{~mm}, 2 \times 4$ groups \\
\hline Source size & $1.0 \mathrm{~m} \mathrm{x} 0.9 \mathrm{~m}$ \\
\hline Total Voltage & $\leq 60 \mathrm{kV}$ \\
\hline Extraction Voltage & $\leq 15 \mathrm{kV}$ \\
\hline $\begin{array}{l}\text { RF Power } \\
\begin{array}{l}\text { Pulse length } \\
\text { Plasma } \\
\text { Extraction }\end{array}\end{array}$ & $\begin{array}{l}3600 \mathrm{~s} \\
10 \mathrm{~s} \text { every } 150-180 \mathrm{~kW}\end{array}$ \\
\hline
\end{tabular}

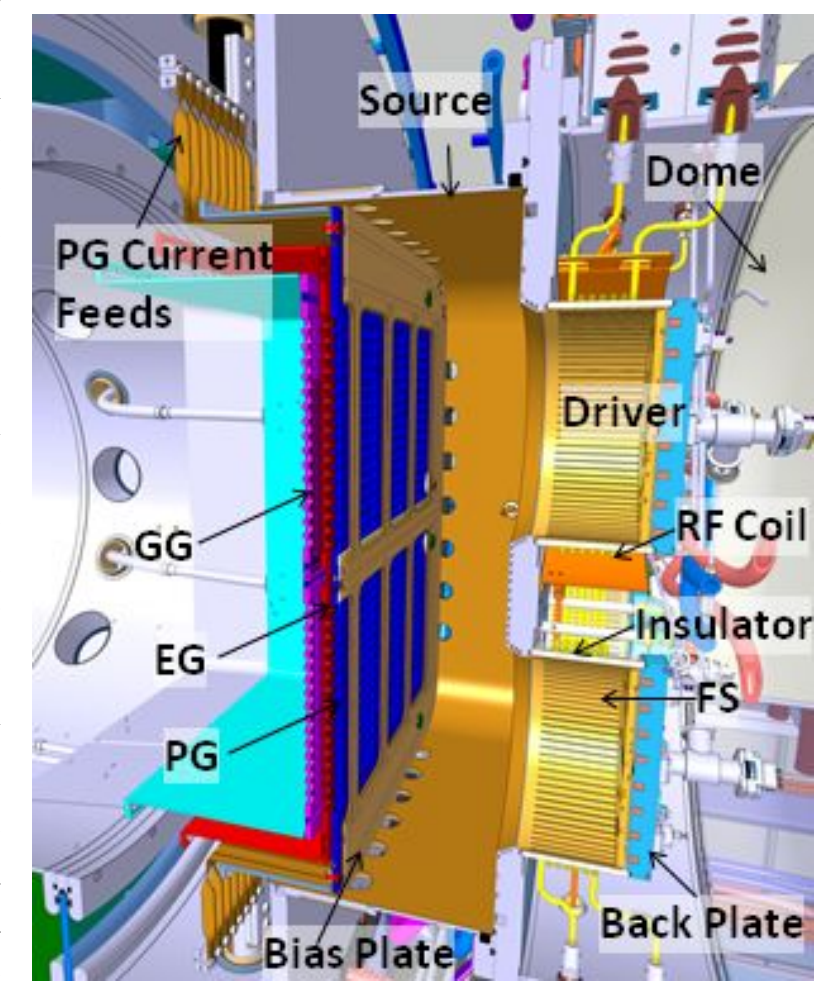

FIG. 1. Cut through the ELISE source with the extraction system: plasma grid (PG), extraction grid (EG) and grounded grid (GG). 
drifts of the electrons in the filter field and the distribution of the production rate of negative ions at the plasma grid.

The magnetic filter field is needed to cool down the electrons in the extraction region in front of the plasma grid to a temperature of around $1 \mathrm{eV}$ at which the destruction of the negative ions by electron collisions is negligible, to minimize the amount of coextracted electrons, and to bent back the negative ions on their way from the plasma grid surface towards the extraction apertures [15]. The filter field is created at the large ITER-relevant sources like the one for ELISE by a current running through the plasma grid (see Ref. [16] and FIG. 1). The resulting field forms a $3 \mathrm{D}$ magnetic field

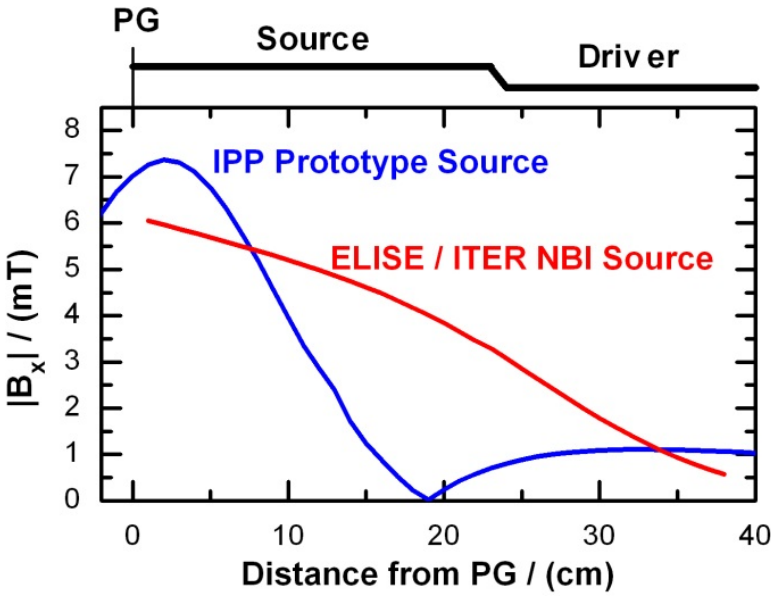

FIG. 2. Comparison of the horizontal magnetic filter field from the plasma grid (PG) to the driver for the small IPP prototype source (permanent magnets) and the larger ELISE / ITER source for the nominal value of $4 \mathrm{kA}$. pattern which is completely different from that of the small RF prototype source $(0.3 \mathrm{~m} \times 0.6 \mathrm{~m})$ where it is generated by permanent magnets [17] and the basic experience for the processes in RF driven sources was gained. FIG. 2 shows a comparison of the filter fields clearly indicating the different field gradients.

For the IPP prototype source it was demonstrated that the plasma in front of the plasma grid is rather homogeneous if the source operates at high production rate of negative hydrogen ions and a low amount of co-extracted electrons [18]. Furthermore, even when the plasma is inhomogeneous, the beam homogeneity was rather good [19]. This is explained by the production of the negative ions at the cesiated plasma grid with a low work function predominantly by the conversion of neutrals [20]; the neutral flux onto the plasma grid, however, is intrinsically much more homogeneous. The extrapolation of this experience and also of the present methods to achieve the required high negative current densities to the much larger ITER-relevant sources is still an open point; especially the Cs distribution and control might be changed due to the larger volume to surface ratio.

Another difference to the small IPP prototype source is that the bias plate surrounds the apertures not only at the edges of the source but also within the plasma centre (see FIG. 1 and FIG. 3). This bias plate extends the source body potential to the plasma grid apertures, and supports so the suppression of the amount of co-extracted ions [21]. This is especially important for deuterium operation as the amount of coelectrons is here much larger than in hydrogen [15].

In order to resolve these issues and to improve the understanding of the behaviour of such large negative hydrogen ion sources, ELISE is equipped with a rather flexible magnetic filter field system [16] and with dedicated diagnostic tools which have been all tested and optimized at

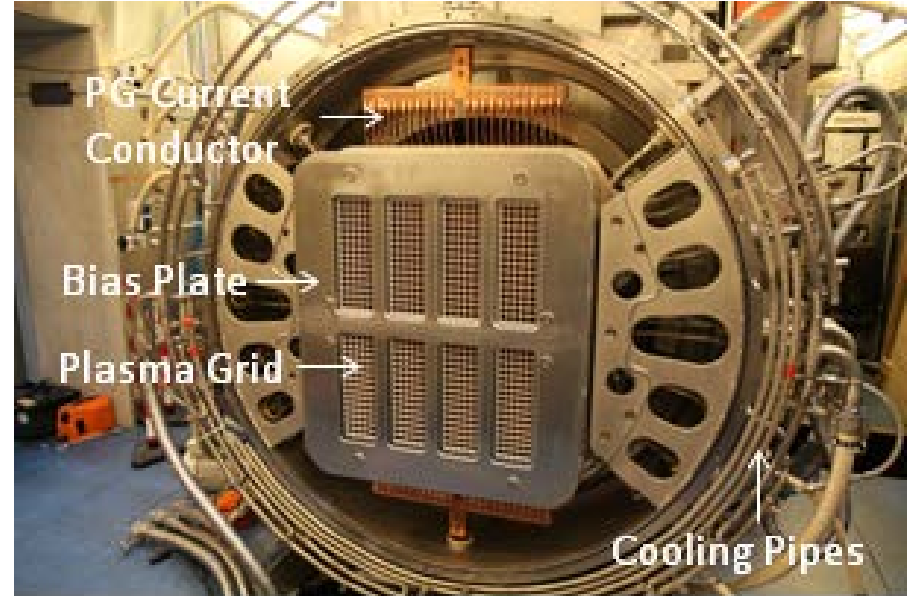

FIG. 3. Extraction system assembly within the HV flange and the plasma grid current conductors. 
the IPP test facilities. In order to have some experimental margins, the ELISE current circuit is designed for $8 \mathrm{kA}$, twice the nominal PG current for ITER NBI. The 3D pattern of the filter field can be changed in a certain amount by changing the geometry of the current return conductors - presently consisting of three individual conductors near the drivers - and the current distribution within [16]. Furthermore, permanent magnets can be attached to the ion source walls.

The plasma homogeneity is measured at ELISE by optical emission spectroscopy (OES) by using of 10 lines-of-sight [22], corresponding to the number of spectrometer channels presently available. In preparation is also the installation of two fixed Langmuir probes in "double probe" configuration for an easy measurement of the plasma density in the top and the bottom part of the source. Both measurements (OES, probes) are done in the boundary layer near the plasma grid (see the diagnostic ports in FIG. 4), where all the processes of negative hydrogen ion

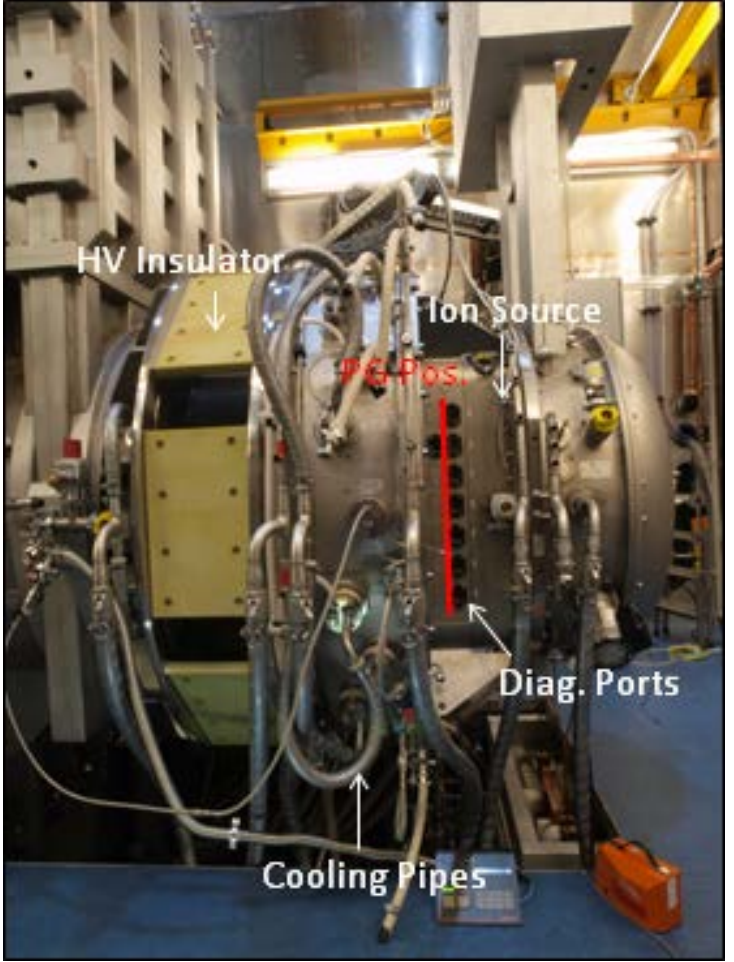

FIG. 4. Ion source assembly with the diagnostic ports near the plasma grid. The plasma grid position is indicated by the line. production and extraction take place [12].

The neutral cesium distribution will be measured by fast diodes ( $1 \mathrm{~ms}$ temporal resolution) equipped with interference filters at $852 \mathrm{~nm}$. A strong emphasis is laid at ELISE on the measurement of the beam homogeneity [23] because this is the important parameter for a high transmission of the beam, i.e. with minimized losses, through the beam line of the ITER NBI system. The beam homogeneity is measured by using beam emission spectroscopy with 20 line-of-sights, a tungsten wire mesh calorimeter which can resolve at least the intensity differences of the eight beamlet groups - each group consists of 5x16 apertures - and a diagnostic beam calorimeter equipped with thermocouples and a blackened surface for thermography. Additionally, both the two segments of the extraction and the grounded grid have been designed to be insulated against each other so that the currents onto the grids can be measured individually. This will also give some information about the homogeneity of the co-extracted electron and the extracted ion current.

ELISE has started operation with first low power beam and plasma pulses in 2013. The paper discusses the commissioning phase of ELISE and shows the first experimental results. Some features of beam and plasma operation w/o Cs, i.e. w/o generating large amounts of negative hydrogen ions, are shown. Emphasis is laid especially on the Faraday screen (being part of the RF drivers, see below) operation as this was regarded as the main technological risk due to the experience with damages at the former test facility RADI [24]. The reason for the local melting there was addressed - but w/o dedicated proof - to bad vacuum conditions and to an inhomogeneous RF magnetic field.

Finally the experimental plan for the remaining $1 \frac{1}{2} 2$ years of operation - covered by the F4E service contract for the establishment and exploitation of ELISE - is discussed. 


\section{Manufacturing and assembly}

The manufacturing and the assembly of ELISE took in total about 12 months longer than it was planned [25], mainly due to problems in the manufacturing of the ion source and in severe delays of the Mo coating of the plasma grid and the bias plate, although experienced manufacturers have been chosen. Mo coating of those components (and of the Faraday screens) made out of electrodeposited copper is necessary to avoid $\mathrm{Cu}$ sputtering; $\mathrm{Cu}$ in turn deteriorates the Cs layer and hence the work function at the plasma grid surface. The

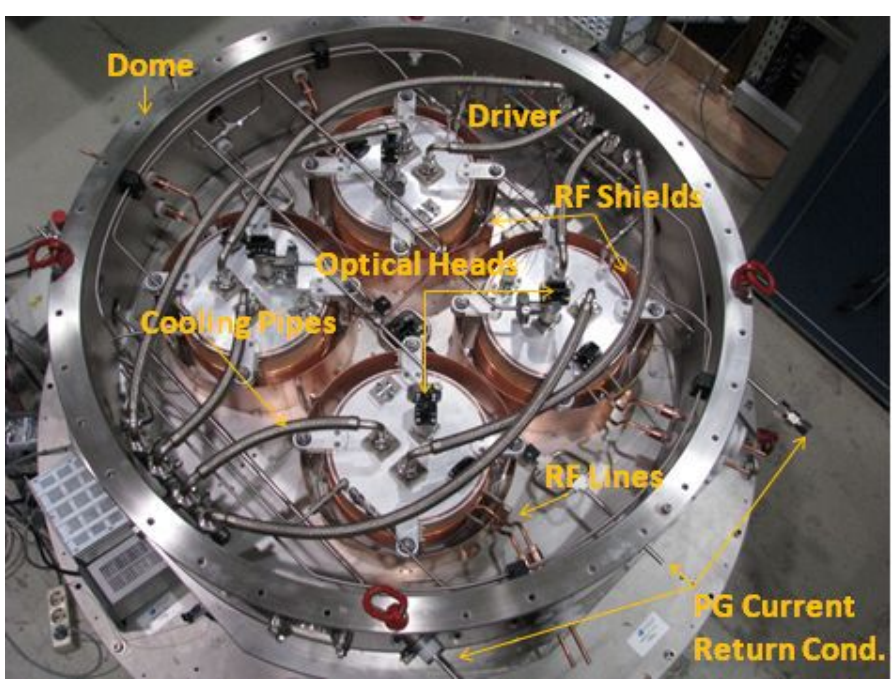

FIG. 5. Driver assembly within the dome with the copper RF shields. manufacturing of the grids was done without problems; the latter is especially important as it ensured also the manufacturing of such large grids for the ITER neutral beam system.

The assembly was finished end of 2012 (see Figs. 3-5). Almost all diagnostic ports with lineof-sights parallel the plasma grid - in total 14, seven for each side of the source - and perpendicular to the plasma grid - in total 19, five in the source backplate and four in the backplates of each driver - have been provided with optical heads for optical emission spectroscopy in order to have a flexible system for the 10 available spectrometer channels [22]. Each optical head is equipped with three line-of-sights with a distance of $1.4 \mathrm{~cm}$ each for some profile measurements. Presently, the used LoS near the plasma grid have a distance of $3.4 \mathrm{~cm}$ to it and a distance of $2.1 \mathrm{~cm}$ to the bias plate, respectively.

Presently, ELISE is equipped with a simple beam dump calorimeter, consisting of four copper plates of $0.6 \times 0.6 \mathrm{~m}$ area with limited diagnostic capabilities (total beam power, the power on each plate and 16 thermocouples in total). The dedicated diagnostic calorimeter with a much better spatial resolution is now ready for installation after some delays in the manufacturing.

\section{Control and commissioning of subsystems}

ELISE is operated by a system of distributed Siemens S7 PLC units supervised by a master control. The typical cycle time is $2 \mathrm{~ms}$, sufficient for most of the needs; for the timing and the control of the HV, however, a dedicated S7 PLC with $1 \mu$ s is installed. Different pulse scenarios have been defined according to the experience with the small IPP test facilities (see table 2) with different subsystems that must be available and operating for starting a pulse. The most demanding operational mode is of course beam extraction in deuterium, where also the radiation protection system is required to be operational due to the produced neutrons from DD reactions in the calorimeter. The radiation protection system consists of three ${ }^{3} \mathrm{He}$ neutron dose rate counters and two thermoluminescent dosimeters distributed around the concrete neutron shield; the latter was designed so that for 6 hours of deuterium beam operation per year the dose rate outside ELISE is below the yearly German public area limit of $1 \mathrm{mSv}$. After the first phase of deuterium operation, some radiation protection measures are also necessary for the maintenance phases due to the activation of the components.

Table 2 lists only the subsystems which are mandatory for the respective operational scenario. Other systems like bias or PG current power supplies are in principle not mandatory for the 
TABLE II: OPERATIONAL SCENARIOS OF ELISE AND REQUIRED SUBSYSTEMS.

\begin{tabular}{|l|c|c|c|c|c|c|c|c|}
\hline \multirow{2}{*}{$\begin{array}{l}\text { Mode of } \\
\text { Operation }\end{array}$} & \multicolumn{7}{|c|}{ Subsystems needed } \\
\cline { 2 - 11 } & CoDaQ & Vacuum & Gas & Cooling & RF & HV & Safety & $\begin{array}{l}\text { Radiation } \\
\text { Protection }\end{array}$ \\
\hline Maintenance & - & - & - & - & - & - & - & $(+)$ \\
\hline Standby & + & + & - & - & - & - & - & - \\
\hline Filament Pulse & + & + & - & - & - & - & - & - \\
\hline Gas Pulse & + & + & + & - & - & - & - & - \\
\hline RF Pulse & + & + & + & + & + & - & + & - \\
\hline HV Pulse w/o Gas & + & + & - & + & - & + & + & - \\
\hline HV Pulse with Gas & + & + & + & + & - & + & + & - \\
\hline Beam Pulse in H & + & + & + & + & + & + & + & - \\
\hline Beam Pulse in D & + & + & + & + & + & + & + & + \\
\hline
\end{tabular}

scenarios. Beam pulses, for example, can be started without having them operational, although it is not quite meaningful at all. The pulses will then be stopped by other interlocks, like the EG power interlock as most probably the amount of co-extracted electrons is by far too large. The same is valid for the physical diagnostics like OES or the Langmuir probes; pulses without having them operational, are possible. Other measurements which are needed for safety and interlocks (see below) must of course be present.

Table 3 shows a list of the most important interlock and safety parameters. The most important interlock is the power on the extraction grid due to the co-extracted electrons which are deflected to rather localized areas (some $\mathrm{mm}^{2}$ ) with very high power densities well above $10 \mathrm{MW} / \mathrm{m}^{2}$. The experience at the small IPP test facilities showed that this power load limits the performance and the long pulse operation of the source [26,27], especially for deuterium operation due the much larger amount of co-extracted electrons. The extraction grid (EG) of ELISE is especially designed for increased power load capabilities [28] with $400 \mathrm{~kW}$ (200 kW per segment) total power and a maximum power density of $32 \mathrm{MW} / \mathrm{m}^{2}$. The power limit corresponds to an extracted electron current density of $400 \mathrm{~A} / \mathrm{m}^{2}$ for $10 \mathrm{kV}$ extraction voltage. This allows so the operation of the EG grid for larger values of the electron/ion ratio than it is required by ITER and gives hence more experimental margin, especially for deuterium operation. As the local power density cannot be measured for all of the 640 apertures — the power density distribution changes also with the filter field - , the EG protection interlock must rely on the total power and on the quality of the power limit calculations. The total power is calculated by the control system from the measured EG currents and voltage, separately for each segment. The experience with the same interlock systems operational at the other IPP test facilities is quite encouraging.

Almost all subsystems (see table 2) have been commissioned without any problems with the exception of the RF generators and the cryo system [25,29]. The former was especially surprising and unexpected, as the generators have been used at the same place in the experimental hall several years before for the RADI test facility [30] without major problems. The only change was the upgrade of the cooling and the low voltage supply for the $\mathrm{cw}$ operation at full power. The problem was that during the first tests at a $50 \mathrm{Ohm}$ test load the 
TABLE III: MAIN SAFETY AND INTERLOCK MEASURES.

\begin{tabular}{|c|c|c|c|}
\hline System & Measurement & Protection & Remarks \\
\hline \multicolumn{4}{|c|}{ Safety } \\
\hline \multirow[t]{2}{*}{$R F \& H V$} & door contacts & personnel & $\begin{array}{l}\text { no access to RF and } \mathrm{HV} \text { areas } \\
\text { during pulse }\end{array}$ \\
\hline & HV grounders & personnel & closed for access to HV areas \\
\hline $\begin{array}{l}\text { Radiation } \\
\text { Protection }\end{array}$ & neutron dose \& dose rate & personnel & max. $1 \mathrm{mSv} / \mathrm{a}$ in public areas \\
\hline \multicolumn{4}{|c|}{ Interlocks } \\
\hline Cooling & $\begin{array}{l}\text { water flow \& } \\
\text { temperature }\end{array}$ & $\begin{array}{l}\text { all water } \\
\text { cooled } \\
\text { components }\end{array}$ & $\begin{array}{l}\text { different limits for the different } \\
\text { components; no large temperature } \\
\text { differences between components }\end{array}$ \\
\hline \multirow[t]{3}{*}{$R F$} & RF current & RF generator & maximum $80 \mathrm{~A}$ \\
\hline & driver light emission & RF generator & $\begin{array}{l}\text { fast diode measurement, ignition } \\
\text { recognition }\end{array}$ \\
\hline & dome pressure & RF coils & $\begin{array}{l}\text { for driver operation in vacuum, } \\
\text { maximum } 10^{-4} \mathrm{mbar}\end{array}$ \\
\hline \multirow[t]{3}{*}{$\begin{array}{l}\text { Gas \& } \\
\text { Vacuum }\end{array}$} & inlet pressure & operation & $\begin{array}{l}\text { avoid pressure in the Paschen } \\
\text { minimum within the gas pipes }\end{array}$ \\
\hline & cryo panels temperature & operation & maximum $30 \mathrm{~K}$ \\
\hline & tank pressure & operation & maximum $10^{-3}$ mbar w/o pulse \\
\hline \multirow[t]{2}{*}{ HV } & power on EG & $\begin{array}{l}\text { extraction } \\
\text { grid }\end{array}$ & $400 \mathrm{~kW}$ at maximum \\
\hline & $\begin{array}{l}\text { number of HV break- } \\
\text { downs }\end{array}$ & $\begin{array}{l}\text { extraction } \\
\text { grid }\end{array}$ & typically 7 interrupts per second \\
\hline
\end{tabular}

main power switches at both generators and subsequent the diodes in the rectifier circuit burned out for unknown reasons. After the replacement of the main switches, the generators could be fully commissioned (see FIG. 6). The commissioning of the cryo system suffered from a defect LHe heater and a leak of the vacuum insulation of the LHe dewar; also both systems had been used before at the MANITU test facility [27].

For cost reasons, ELISE uses one of the IPP main HV power supplies (ratings are $100 \mathrm{kV}$, $100 \mathrm{~A}, 10 \mathrm{~s}$ at maximum) which was rebuilt for a separate delivery and control of both the extraction and the acceleration voltage as well for the simultaneous supply of the BATMAN test facility [17]. Furthermore, the HV control system - consisting of two linear, tetrode based HV-regulators - was moved from the MANITU test facility, reinstalled and commissioned together with the HV power supply on a test load without any problems. 


\section{Basic RF Operation}

As it is the case also for the ITER NBI sources, each of the two RF generators feed two drivers in series (see FIG. 7). The matching of the load to the generator is done by a combination of a parallel $\left(\mathrm{C}_{1}\right)$ and a series $\left(\mathrm{C}_{2}\right)$ capacitor, the latter being remotely tuneable for a possible change of the matching during a pulse. In order to distribute the RF voltage equally between the coils, the series capacitor is placed in between the coils. Presently, the transformer is done in a 3:1 configuration; this turn ratio as well as the arrangement of coils and capacitors can be changed very easily to test other configurations. The transformer is needed at ELISE as the generators are placed on ground potential. In order to minimize the RF noise by avoiding large ground loops, the generator is grounded at the ion source. The quality of matching is expressed in the following by the cosine of the phase angle between the RF current and voltage ("cos $\varphi$ ").

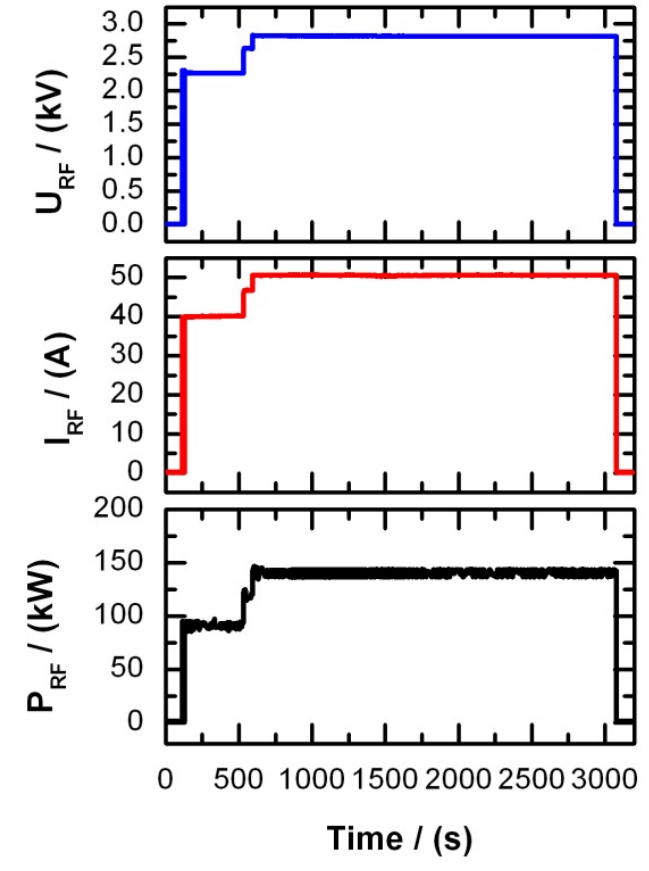

FIG. 6. First long $140 \mathrm{~kW}$ RF pulse at a testload.

RF operation with the ion source attached, i.e. with plasma, was started in February 2013. In order to keep the risk for damaging the Faraday screens as low as possible, following countermeasures have been performed:

- The source was baked out for several days with temperatures of up to $350 \mathrm{~K}$ in order to reduce the amount of impurities.

- Additional RF shields surrounding the drivers and made out of copper have been installed (see FIG. 5) like it was tested at RADI.

- The power was limited to $40 \mathrm{~kW}$ per generator for the first operational phase.

- The impurity level in the drivers has been carefully supervised by using four channels of the standard low-resolution spectrometers (PLASUS EMICON MC System, $\lambda=180-880 \mathrm{~nm}$, sampling rate $<15 \mathrm{~Hz}$ ) and, additionally, by a high resolution Echelle survey spectrometer (LLA Instruments ESA 3000, $\lambda=200-$ $780 \mathrm{~nm}$, sampling rate $\approx 0.2 \mathrm{~Hz}$ ).

The results are shown in FIG. 8 and FIG. 9. FIG. 8 shows a comparison of the RF matching for pulses with only one generator or both. The matching changes with time due to the $1 \mathrm{~s}$ gas puff needed for ignition, by a change of the matching capacity and by a change of the pressure in the second part of the pulse. The figure, however, clearly indicates, that the matching of one RF circuit does not depend whether the other drivers are powered or not and can be attributed to the RF shields around the drivers.

FIG. 9 shows an example of a spectrum in the visible range for the conditions shown in FIG. 8. The spectrum is dominated by the hydrogen Balmer lines and the Fulcher lines of the hydrogen molecule; line radiation from

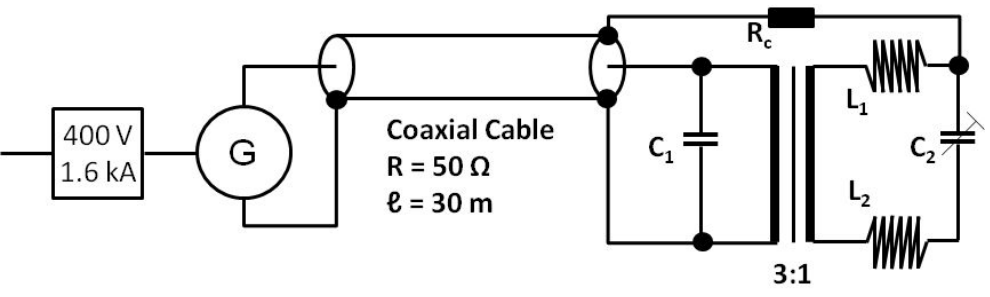

FIG. 7. RF circuit of ELISE of one generator $(G)$ with the two coils/drivers $\left(L_{1}, L_{2}\right)$ in series. 
impurities is not present. Especially, the copper lines at around $515 \mathrm{~nm}$ are missing; the presence of this line was at RADI a clear indication of the melting of the Faraday screens. Also, the oxygen content is below the detection limit - clear oxygen emission lines should be present at around $777 \mathrm{~nm}$. This will be beneficial for the operation of ELISE with Cs as its dynamics and transport is mainly determined by the Cs chemistry, i.e. compound formation.

After this successful start of the RF operation the plasma pulse length was gradually increased (still with low power) to $4 \mathrm{~min}$ w/o major problems. Some increase of the pressure in the dome surrounding the drivers with the vacuum decoupled from the ion source itself (see FIG. 1) - from the basic pressure of some $10^{-7}$ mbar to $10^{-5}$ mbar was observed which could be addressed to outgassing of

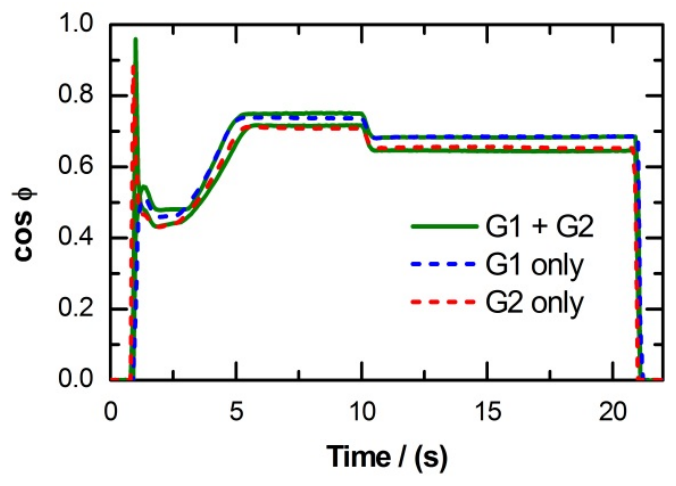

FIG. 8. Matching ( $\cos \varphi)$ of the upper and the lower pairs of drivers for operation with Generator 1 (upper pair) or Generator 2 (lower pair) or both. The matching capacity was changed until 5 seconds; at 10 seconds the pressure was lowered from 0.8 to $0.5 \mathrm{~Pa}$. The RF power was $40 \mathrm{~kW}$ per generator. the coils and other structures within the dome.

Hence, a dedicated baking of the dome components (coils, driver back plates etc.) might be necessary for a further increase of the pulse length.

Additionally, low source pressure operation down to $0.2 \mathrm{~Pa}$ (filling pressure) was possible. This is in-line with the findings at RADI [24]. This unproblematic low pressure operation of the large RF ion sources is a consequence of the much higher gas flow needed for a given pressure compared to the small prototype sources. The measured conductance of the ELISE grid assembly is about $14 \mathrm{~m}^{3} / \mathrm{s}$. This is about 20\% larger than calculated with the standard text book formulas just from the aperture geometry; but this deviation can be explained by some lateral conductance aside of the grid holder boxes. Hence, for the required $0.3 \mathrm{~Pa}$ a gas flow of about $1 \mathrm{~Pa} \mathrm{~m}^{3} / \mathrm{s}$ per driver is needed - about a factor of 3 larger than at BATMAN or MANITU. For the aforementioned gas puff which is mandatory for plasma ignition, a total flow of $17 \mathrm{~Pa} \mathrm{~m} / \mathrm{s}$ for $1 \mathrm{~s}$ is presently needed, achieving a pressure of $1.2 \mathrm{~Pa}$.

\section{First beams}

The beam operation of ELISE was prepared with a phase of grid conditioning in vacuum up to $40 \mathrm{kV}$ total voltage, sufficiently large for starting the grid conditioning with beam. This was done in this first experimental phase w/o Cs, i.e. w/o the generation of a large amount on negative hydrogen ions. Hence, the 'beam' consists mainly out of electrons, which are deflected onto the extraction grid. In order to avoid a damage of this grid (see above), the plasma parameters have been chosen for keeping the current of the co-extracted electrons as low as possible. This means operation at low RF power $(2 \times 40 \mathrm{~kW})$, high pressure $(0.7 \mathrm{~Pa})$, sufficient high plasma grid bias ( $>20 \mathrm{~A}$ in current controlled mode) and sufficient high

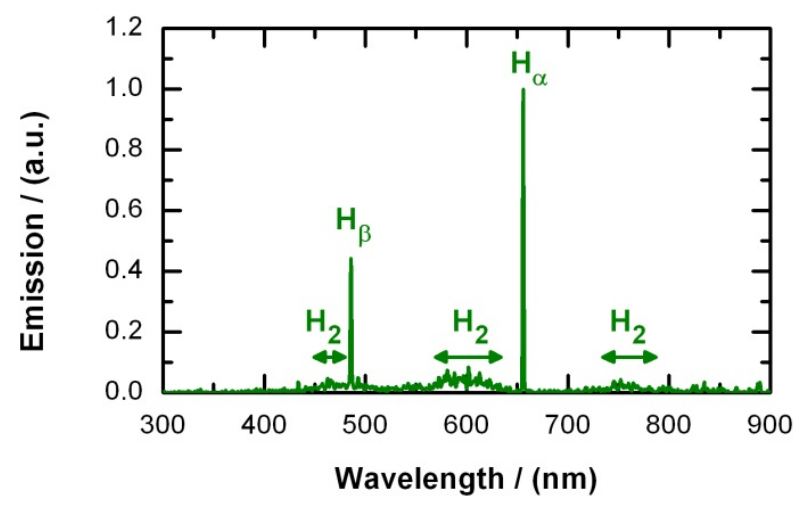

FIG. 9. One of the first emission spectra of the ELISE plasma. RF power was $2 \times 40 \mathrm{~kW}$, filling pressure 0.6 Pa. 
magnetic filter field (>3 kA plasma grid current - $3 \mathrm{kA}$ correspond to about $2.9 \mathrm{mT}$ maximum field in front of the plasma grid in the present configuration [16]). Additionally, the interlock value of the extraction grid power was gradually increased from $50 \mathrm{~kW}$ per grid segment to $75 \mathrm{~kW}$.

FIG. 10 shows a schematic overview of the $\mathrm{HV}$ circuit of ELISE. The ions are accelerated to a

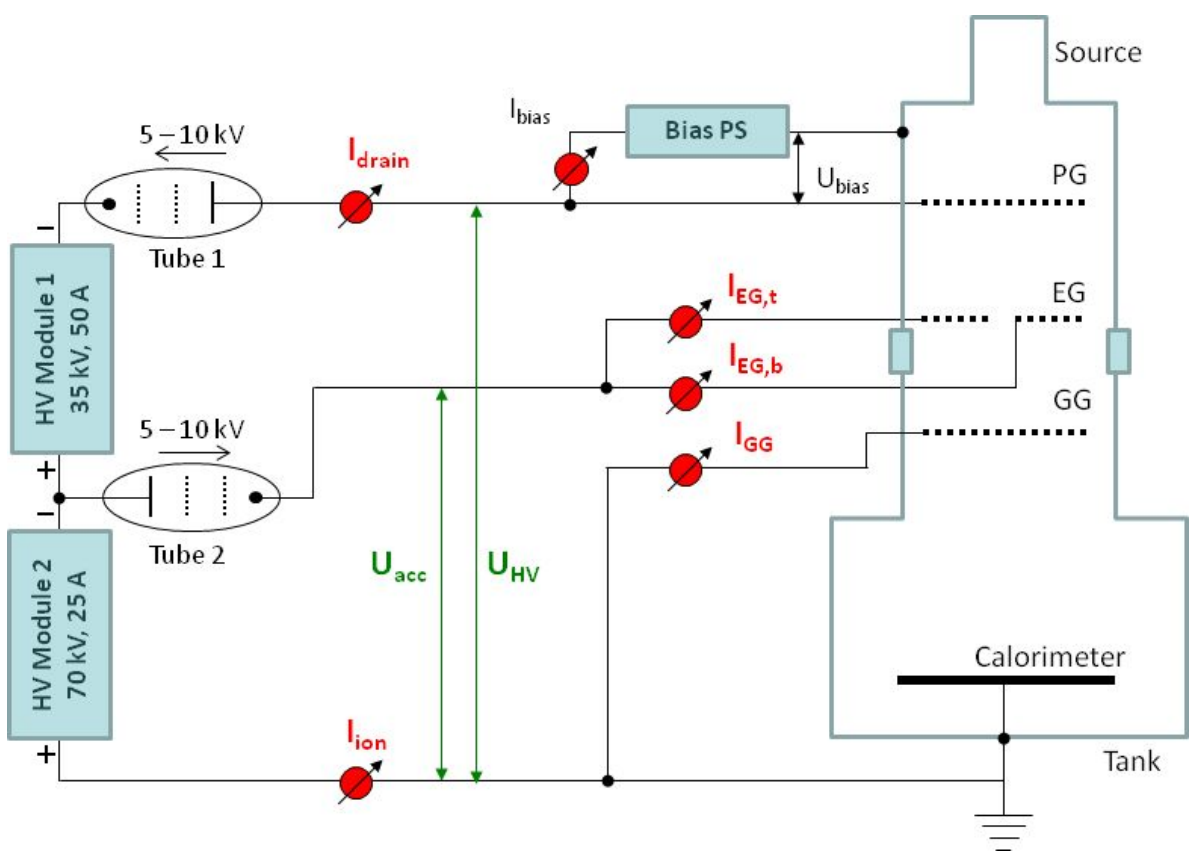

FIG. 10. Scheme of the HV circuit of ELISE with the voltage and current measurements. The voltage is regulated by tetrodes. calorimeter located at a distance about $3.5 \mathrm{~m}$ from the GG. The source is at a high potential with a maximum voltage of $60 \mathrm{kV}$; regulated are the total voltage $\left(\mathrm{U}_{\mathrm{HV}}\right)$ and the acceleration voltage $\left(\mathrm{U}_{\mathrm{acc}}\right)$ between the extraction and the ground grid. The extraction voltage $\left(U_{e x}\right)$ is then just the difference between those two.

The electrical currents flowing from the power supply to the source (“drain current"), as well as the currents flowing back from the different components to the $\mathrm{HV}$ power supply, are measured individually. The current on both of the extraction grid segments and on the grounded grid, respectively, can be caused in principle both by electrons and by negative ions; there are however indications [31] that for the measurements reported here the current on the extraction grid can reasonably well be assumed to be solely caused by impinging electrons and the current on the grounded grid and on the beam line components (calorimeter) to be solely caused by negative hydrogen ions. This is in agreement also with the findings for the small IPP prototype source [17]. Hence, the ' $\mathrm{I}_{\mathrm{EG}}$ ' current measurements gives the current of electrons hitting the extraction grid segments, i.e. the 'co-extracted electron current' and the ' $\mathrm{I}_{\text {ion }}$ ' current measurement gives the current of negative hydrogen ions being extracted from
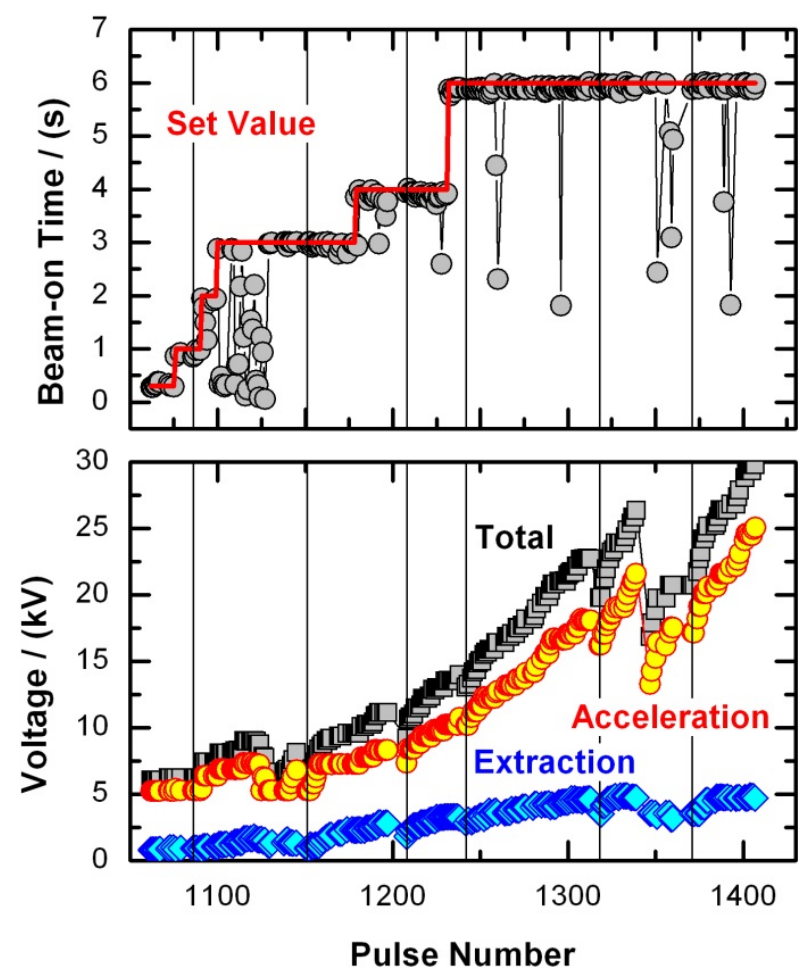

FIG. 11. Grid conditioning at ELISE with beam pulses. RF power was $2 \times 40 \mathrm{~kW}$; bias current $20 \mathrm{~A}$, source filling pressure 0.6-0.7 Pa, PG filter field current $3 \mathrm{kA}$. The vertical lines indicate the seven operational days. 
the plasma grid, i.e. the 'extracted ion current'.

FIG. 11 shows the daily progress of the grid conditioning during the first seven days of operation. Voltages of $30 \mathrm{kV}$ (total), $25 \mathrm{kV}$ (acceleration) and $5 \mathrm{kV}$ (extraction) have been achieved, respectively, for 6 seconds. The cloud of pulses with rather short beamon times at the second day of operation was used for some basic checks and error handling of the $\mathrm{HV}$ control system and for an increase of the number of allowable breakdowns from 1 to 7 per second until the HV systems trips.

FIG. 12 shows the dependence of the extracted currents on the extraction voltage. As mentioned above, the current at each of the two extraction grid segments is measured individually. The overall current accountability is quite good (see FIG. 13): the sum of the three currents (ion current and the currents at the two extraction grid segments) is within $5 \%$ of the total drain current. FIG. 12 shows some features which will be addressed in detail in the next experimental campaigns:
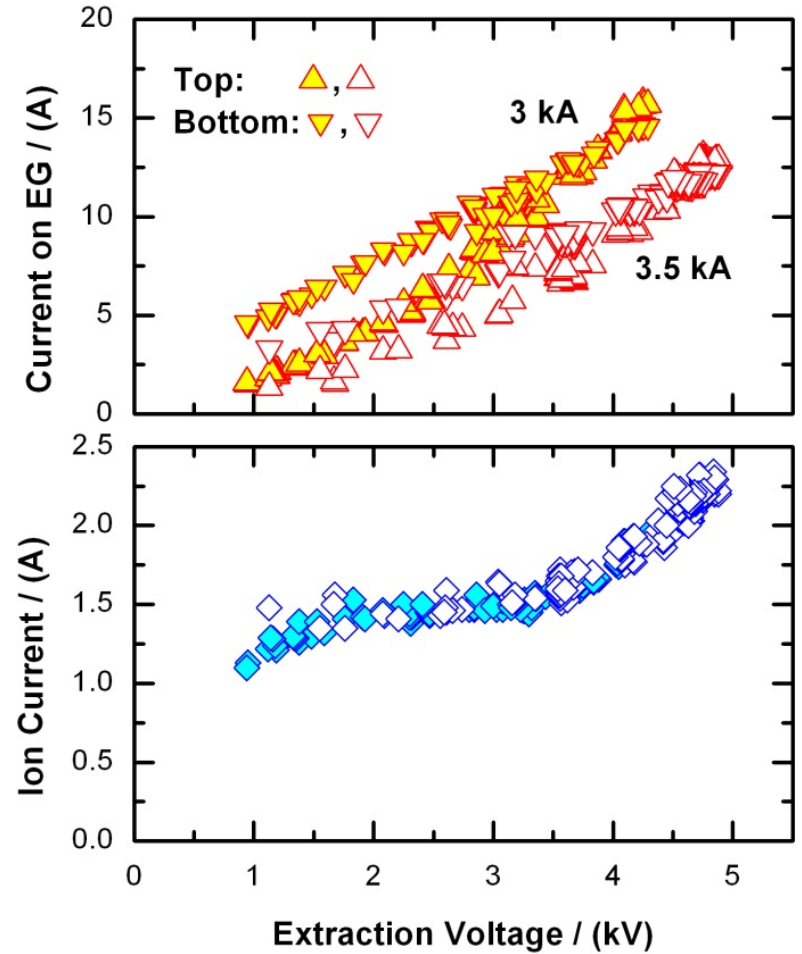

FIG. 12. Dependence of the extracted currents on the extraction voltage in volume operation, i.e. w/o Cs. RF power was $2 \times 40 \mathrm{~kW}$, source filling pressure $0.6 \mathrm{~Pa}$, PG filter field current $3 \mathrm{kA}$ (closes points) and $3.5 \mathrm{kA}$ (open points).

- The electron current can be suppressed reasonably with the magnetic filter field (and PG bias, not shown here) even in volume operation. An increase of the PG current from 3 to $3.5 \mathrm{kA}$ decreases the amount of co-extracted electrons by $30 \%$; this was necessary as the power on both of the extraction grid segments reaches the interlock limit of $75 \mathrm{~kW}$ (15 A x $5 \mathrm{kV}$ ). This is very encouraging also for the operation with Cs, especially when taking the effect into account that the plasma homogeneity [22] and the plasma parameters changes only slightly for these high fields. More details can be found in Ref. [31].

- Even more striking is the observed top/bottom asymmetry of the measured currents on the top and bottom extraction grid segments, indicating also an asymmetry in the electron extraction. The asymmetry changes with extraction voltage (as shown in the figure), but also with bias and filter field. The current path in the plasma grid and the remaining magnetic filter field direction is presently so that the drift of the

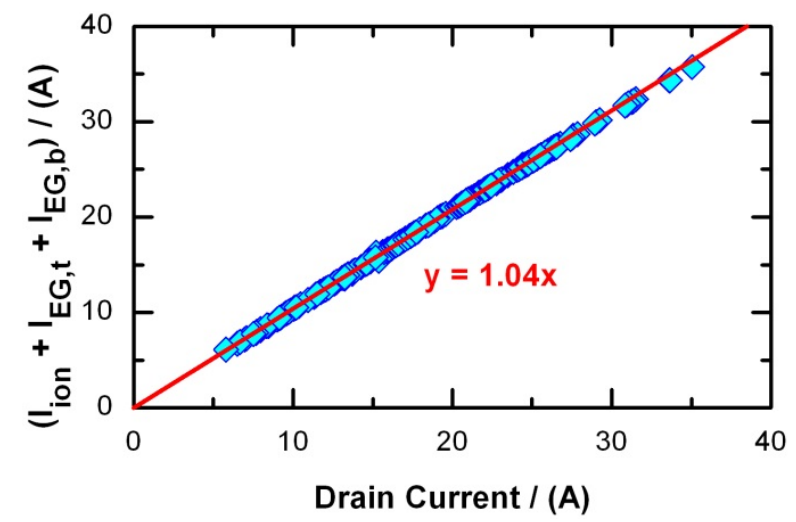

FIG. 13. Current accountability at ELISE. I ion denotes the 'Ion' current, i.e. the current flowing back from ground potential to the $H V$ power supplies, $I_{E G, t}$ and $I_{E G, b}$ denotes the currents on the upper and the lower extraction grid segment. 
electrons is upwards, but at a first glance the observed asymmetry is not correlated with the plasma homogeneity measured in a distance of $3.4 \mathrm{~cm}$ from the plasma grid. Again, more details with more experimental data and a discussion of the possible reasons can be found in Ref. [31].

- The dependence of the ion current on the extraction voltage is non-linear with a plateau between 1.5 and $3.5 \mathrm{kV}$. There is also no influence of the magnetic filter field. Although this dependence in volume operation is not important for Cs operation, where the negative hydrogen ions are generated at the plasma grid surface, this data may be an important input for the understanding and modelling of large RF driven hydrogen ion sources. Nevertheless, some negative

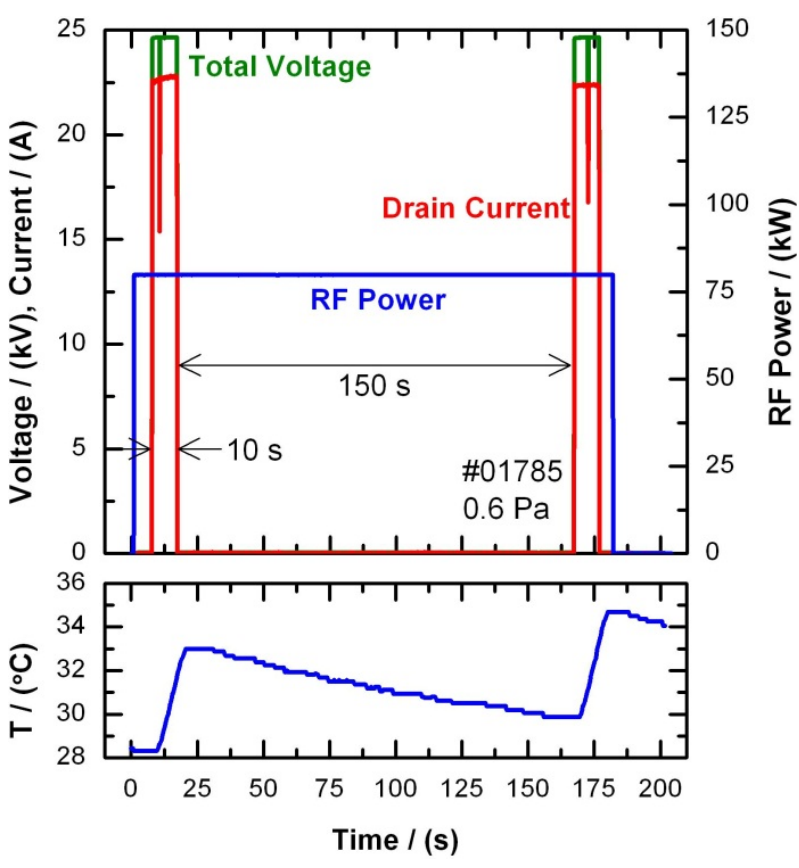

FIG. 14. First pulsed beam extraction: every $150 \mathrm{~s}$ a $10 \mathrm{~s}$ beam pulse is performed (top). The resulting beam is seen also by the increase of the temperature of the calorimeter (bottom). ion beam is extracted; as measurements of the grounded grid current shows, about $65 \%$ of the ions are lost there. The remaining part hits the beam dump calorimeter, as can be seen an increase of the temperature of a few K measured by thermocouples (see FIG. 14).

- These high electron and ion currents for the rather low applied RF power - also the ion current is with a value of $2-3 \mathrm{~A}$, corresponding to $20-30 \mathrm{~A} / \mathrm{m}^{2}$, quite large for volume operation - indicates also a larger RF efficiency than the smaller IPP prototype source: for a similar pressure $(0.6 \mathrm{~Pa})$ in volume operation, about $70 \mathrm{~kW} \mathrm{RF}$ power per driver was necessary at BATMAN for the same extracted ion current (see Ref. [17], the quoted measured RF power there is too large by $30 \%$ ).

Finally, FIG. 14 shows the successful demonstration of the pulsed beam operation for long pulses. As mentioned above, only beam pulses of up to $10 \mathrm{~s}$ every $150 \mathrm{~s}$ are possible due to the technical limits of the IPP HV power supply. As the Cs dynamics in a negative hydrogen ion source is determined by the redistribution processes during the plasma phase, this kind of pulsed extraction is sufficient for the investigation of the long pulse beam stability. This was demonstrated by the small scale, but long pulse MANITU test facility [27] by a comparison of pulsed with continuous extraction.

\section{Experimental plan}

After successfully commissioning ELISE with first plasma and low power beam pulses the experiments are now on-going. The experimental plan is aiming at the demonstration of a full power beam at the required parameters (see table 1 and FIG. 15), within the 2 years of operation until end of 2014 which is covered by the F4E contract for the construction and exploitation of ELISE. The outcomes are relevant for SPIDER \& MITICA commissioning and operation, and for HNB/DNB design finalization phases. An important outcome of the first experimental phase was already the insertion of the RF shielding rings around the drivers 
leading to a non-problematic operation of the Faraday screens; this design change is now under discussion for the SPIDER/MITICA source.

The plan is structured in blocks of 6 months with different issues that will be tackled and/or solved. Of course, the plan may change due to the out comings of the experiments (including possible damages etc.) and new issues that have to be solved during the design phase of MITICA and the DNB/HNB's at ITER. In the following the 6month blocks are discussed in more detail.

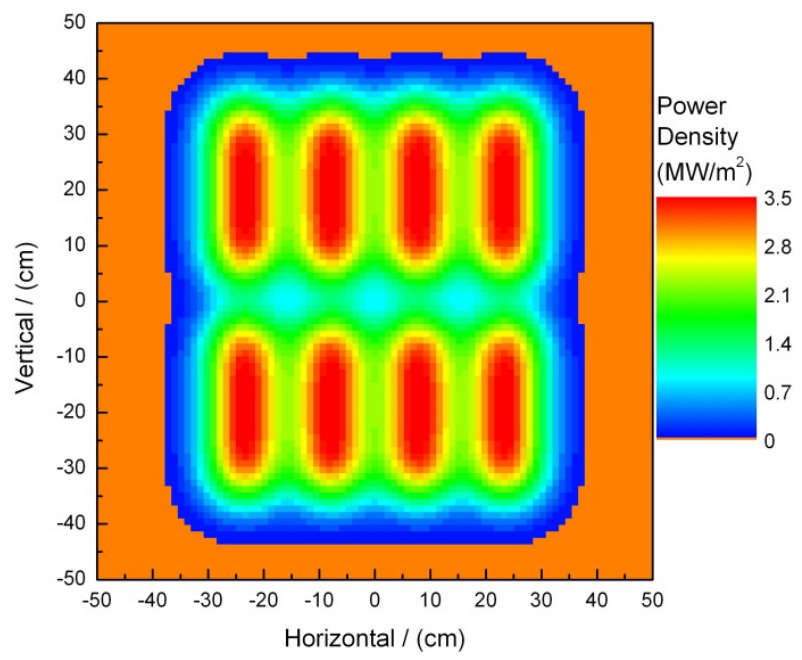

\subsection{Phase 1 (month 1-6): initial experiments \\ FIG. 15: Calculated ELISE full power beam profile at the calorimeter $\left(20 \mathrm{~A}, 60 \mathrm{kV}, 1^{\circ}\right.$ divergence).}

This first phase of the first six months of

operation consists of a gradual approach of the operational parameters to the required ones, without the goal to reach them. The main issues are:

- Plasma homogeneity without Cs, including a check of the plasma overlap in between the drivers with OES, and a comparison with the data of RADI (the predecessor experiment, but without extraction [30]); measurement of the dependence of the plasma inhomogeneity on RF power, filling pressure, bias and magnetic filter field; this topic is now finished (see sections 4 and 5 above and Ref. [22]).

- $\quad$ Plasma \& beam homogeneity studies with Cs at low power in $H$ and $D$ with the first time that Cs will be inserted into the source. This will be done next. In order to minimize the risk of damages, low RF power operation, i.e. $\leq 50 \mathrm{~kW}$ per driver, is foreseen. Start conditions will be as known from BATMAN: PG temperature $150{ }^{\circ} \mathrm{C}$, body temperature $35{ }^{\circ} \mathrm{C}$. Some grid conditioning will be also necessary due to the increasing beam power. The pulse length will be increased to $1000 \mathrm{~s}$ and the first deuterium pulses are planned.

- Optimization of plasma grid bias in hydrogen and deuterium including some first studies of the influence of the magnetic filter field on beam \& plasma homogeneity, current density and electron suppression, as bias voltage and filter field act together $[18,21]$.

\subsection{Phase 2 (months 7-12): optimization in hydrogen}

The second phase will then concentrate of increasing the RF power up to $80 \mathrm{~kW}$ per driver. The experiments in these six months are performed in hydrogen only, for optimization of all parameters. Final goal is to demonstrate a hydrogen beam near/at/exceeding the requirement parameters for several $100 \mathrm{~s}$. The topics here are:

- $\quad$ Plasma \& Beam Homogeneity with Cs at High Power in Hydrogen including a further conditioning of the grids during increasing beam current and measurements of beam homogeneity (calorimeter, grid currents, beam emission spectroscopy), comparison with plasma homogeneity

- Optimization of the magnetic filter field in the interaction with the PG bias. Main emphasis will be laid on electron suppression and maximizing the current density.

- Optimization of Cs conditioning, i.e. development of fast conditioning scenarios (pulse/pause ratio, source cleaning, Cs monitoring), optimization of source and PG 
temperature w.r.t. source performance (i.e. current densities), but also w.r.t. to conditioning time, investigation of the influence of impurities to the source performance and conditioning time, especially the cryo pump recovery.

\subsection{Phase 3 (months 13-18): optimization in deuterium}

The third phase will then concentrate on the optimization of the source in deuterium operation at high RF power. The issues that will be tackled are the same as in the phase 2 for hydrogen, i.e. optimisation of the magnetic filter field, the PG bias and the Cs dynamics.

\subsection{Phase 4 (months 19-24): final demonstration}

The last phase will then concentrate on the final demonstration of a beam at the required parameters both in hydrogen and deuterium for the required pulse lengths (400 s in H, $3600 \mathrm{~s}$ in D).

\section{Conclusion}

The ELISE test facility has gone successfully into operation with first plasma and beam pulses. It is now ready for the first time for the exploitation of the performance of a large cesiated ITER-relevant RF driven negative hydrogen ion source. This early start is an important prerequisite for establishing the neutral beam system at ITER in-time.

\section{Acknowledgments}

The work was supported by a contract from Fusion for Energy (F4E-2009-0PE-32-01) with an amount of 4 Mio. Euro. The opinions expressed herein are those of the authors only and do not represent the Fusion for Energy's official position.

\section{References}

[1] HEMSWORTH, R. et al. Nuclear Fusion, v. 49, p. 045006, 2009. URL: <doi:10.1088/0029-5515/49/4/045006>.

[2] SCHUNKE, B. et al. AIP Conference Proceedings, v. 1097, p. 480, 2008. URL: <doi:10.1063/1.3112548>.

[3] MASIELLO, A. et al. Fusion Engineering and Design, v. 84(7-11), p. 1276-1280, June 2009. http://dx.doi.org/10.1016/j.fusengdes.2008.12.090.

[4] MASIELLO, A. et al. Proceedings of the 24th IAEA Fusion Energy Conference. 2012. p. ITR/P1-04.

[5] SONATO, P. et al. Proceedings of the 23rd IAEA Fusion Energy Conference. 2010. p. ITR/P1-13. http://wwwpub.iaea.org/mtcd/meetings/PDFplus/2010/cn180/cn180_papers/itr_p1-13.pdf.

[6] SCHUNKE, B. et al. Proceedings of the 24th IAEA Fusion Energy Conference. 2012. p. ITR/P1-03.

[7] ROTTI, C. et al. Proceedings of the 24th IAEA Fusion Energy Conference. 2012. p. ITR/P5-43.

[8] SONATO, P. et al. Proceedings of the 24th IAEA Fusion Energy Conference. San Diego, USA: IAEA. 2012. p. ITR/1-3.

[9] SONATO, P. et al. Fusion Engineering and Design, v. 84, n. 2-6, p. 269-274, 2009. URL: <http://dx.doi.org/10.1016/j.fusengdes.2008.11.095>. 
[10] HEINEMANN, B. et al. Fusion Engineering and Design, v. 84(2-6), p. 915-922, June 2009. http://dx.doi.org/10.1016/j.fusengdes.2008.11.076.

[11] FRANZEN, P. et al. AIP Conference Proceedings, v. 1097, p. 451, 2009. http://link.aip.org/link/?APCPCS/1097/451/1.

[12] FANTZ, U. et al. Nuclear Fusion, v. 49, p. 125007, 2009.

[13] WÜNDERLICH, D. et al. Plasma Physics and Controlled Fusion, v. 54, p. 125002, 2012.

URL: <http://dx.doi.org/10.1088/0741-3335/54/12/125002>.

[14] GUTSER, R. et al. Plasma Physics and Controlled Fusion, v. 51, p. 045005, 2009. URL: <http://dx.doi.org/10.1088/0741-3335/51/4/045005>.

[15] FRANZEN, P. et al. Plasma Physics and Controlled Fusion, v. 53, p. 115006, 2011. URL: <http://dx.doi.org/10.1088/0741-3335/53/11/115006>.

[16] FRÖSCHLE, M. et al. Fusion Engineering and Design, 2013. in press; availabe online.

[17] SPETH, E. et al. Nuclear Fusion, v. 46, p. S220, 2006. http://www.iop.org/EJ/abstract/0029-5515/46/6/S03.

[18] FANTZ, U. et al. AIP Conference Proceedings, v. 1097, p. 265, 2009. DOI:10.1063/1.3112521.

[19] FRANZEN, P.; FANTZ, U.; NNBI-TEAM. AIP Conference Proceedings, v. 1390, p. 310-321, 2011.

[20] WÜNDERLICH, D. et al. 3rd International Symposium on Negative Ions, Beams and Sources (NIBS). 2012. p. to be published in AIP Proceedings.

[21] FRANZEN, P. et al. AIP Conference Proceedings, v. 993, p. 51-54, 2008. URL: <http://dx.doi.org/10.1063/1.2909175>.

[22] WÜNDERLICH, D., 2013. to be published.

[23] NOCENTINI, R. et al. Fusion Engineering and Design, 2013. in press; available online.

[24] FRANZEN, P. Internal Report IPP 4/290, Final Report of Contract F4E-2008-GRT-07 (RFSDE), Max-Planck-Institut für Plasmaphysik, Garching, 2011, 126 pages.

[25] HEINEMANN, B. et al. Fusion Engineering and Design, 2013. in press; availlabe online.

[26] FANTZ, U.; SCHIESKO, L.; WÜNDERLICH, D., 2012. Proceedings of the 3rd Conference on Negative Ions, Beams and Sources; to be published in AIP Conference Proceedings.

[27] KRAUS, W. et al. Review of Scientific Instruments, p. 02B104, 2012. doi: 10.1063/1.3662957.

[28] NOCENTINI, R. et al. Fusion Engineering and Design, v. 86(6-8), p. 916-919, 2011. http://dx.doi.org/10.1016/j.fusengdes.2011.01.147.

[29] KRAUS, W. et al. 3rd International Symposium on Negative Ions, Beams and Sources (NIBS). 2012. to be published in AIP Conference Proceedings.

[30] FRANZEN, P. et al. Fusion Engineering and Design, v. 82, p. 407-423, 2007. http://dx.doi.org/10.1016/j.fusengdes.2007.03.041. 
[31] FRANZEN, P.; WÜUNDERLICH, D.; FANTZ, U. Plasma Physics and Controlled Fusion, 2013. submitted. 